\title{
Spontaneous Intracystic Hemorrhage of the Arachnoid Cyst: A Case Report and Review of Literature
}

\author{
Jha R, ' Sharma GR,' Kumar P,' Roka YB' \\ 'National Neurosurgical Referral Centre, National Academy of Medical Sciences, Bir Hospital, Kathmandu, Nepal
}

\begin{abstract}
Arachnoid cysts represent benign cysts that occur in the cerebrospinal axis in relation to the arachnoid membrane and do not communicate with the ventricular system. We report a case of a years right handed lady, who presented to the emergency department with the complaints of headache and vomiting for one week CT scan showed extraaxial cystic lesion in the left fronto-parietal region. On the fifth day of admission, patient had sudden onset of severe headache associated with loss of consciousness for about 3-4 minutes with neck rigidity.
\end{abstract}

A CT scan of head was repeated, which showed left fronto-parietal cystic lesion with intracystic bleed and SAH. Intraoperatively, there was intradural cystic lesion containing xanthochromic fluid with normal brain surface and there were no evidence of any vascular malformations. Marsupilization of the cystic lesion was carried out and she improved. The literature regarding arachnoid cyst with spontaneous intracranial haemorrhage is reviewed.

Key word: arachnoid cyst, haemorrhage, intracycstic

\section{INTRODUCTION}

Arachnoid cysts represent benign cysts that occur in the cerebrospinal axis in relation to the arachnoid membrane and do not communicate with the ventricular system. They usually contain clear, colorless fluid that is most likely normal cerebrospinal fluid, but they rarely contain xanthochromic fluid. Most are developmental anomalies. A small number of arachnoid cysts are acquired, such as those in association with neoplasms or those that are due to adhesions following leptomeningitis, hemorrhage or surgery. They constitute approximately
$1 \%$ of intracranial masses, with $50-60 \%$ occurring in the middle cranial fossa. Cysts in the middle cranial fossa are found more frequently in males and on the left side.

Arachnoid cysts are often an incidental finding on imaging, and usually, patients are asymptomatic even if the cyst is quite large. The most commonly associated clinical features are headache, calvarial bulging and seizures, with focal neurologic signs occurring less

\footnotetext{
Correspondence:

Dr. Rajiv Jha

National Neurosurgical Referral Centre

National Academy of Medical Sciences

Bir Hospital, Kathmandu, Nepal.

Phone: +977-9851039699

Email: nscn@nscn.wlink.com.np
} 
Jha et al. Arachnoid Cyst

frequently. Controversy surrounds the treatment of arachnoid cysts. Some clinicians advocate treating only patients with symptomatic cysts, while others believe that even in asymptomatic patients, cysts should be decompressed to avoid future complications. The most effective surgical treatment appears to be excision of the outer cyst membrane or cystoperitoneal shunting.

\section{CASE REPORT}

A 47 years Right handed female, presented in the emergency department with the complaints of headache and vomiting for one week. She was apparently well before this episode of illness which started one week back when she had sudden onset of severe headache associated with multiple episodes of vomiting. She does not give any history of fever, trauma or seizure. History was not suggestive of hypertension, diabetes mellitus or tuberculosis. Her vitals parameters were within normal limits with no neurological deficits, no cerebellar signs or signs of meningism.

Her baseline investigations were normal. Cerebrospinal fluid (CSF) analysis was also carried out to rule out either meningitis or subarachnoid haemorrhage. The CSF showed sugar $57 \mathrm{mg} \%$, Protein $59 \mathrm{mg} \%$. Total count 180 cells/Neutrophil 8, Lymphocytes 92 and 4-6 red blood cells (RBCs). So she was started treatment in the line of meningitis. CT scan showed extraaxial cystic lesion in the left fronto-parietal region (Figure 1). On the fifth day of admission, patient had sudden onset of severe headache associated with loss of consciousness for about 3-4 minutes and on examination neck rigidity was present. So computed tomography (CT) scan of head was repeated, which showed left fronto-parietal cystic lesion with intracystic bleed and subarachnoid hemorrhage (SAH) (Figure 2).

$\mathrm{MRI}$ of brain and three-vessel cerebral angiogram was done to rule out venous angioma/cavernous angioma or any underlying vascular pathology. MRI of brain showed left fronto-parietal extradural cystic lesion with intracystic bleed and SAH. Three vessel cerebral angiogram was normal. As the patient had features of raised intracranial pressure, patient was planned for surgery. Intraoperatively, there was intradural cystic lesion containing xanthochromic fluid with normal brain surface and there were no evidence of any vascular malformations (Figure 3). Marsupilization of the cystic lesion was carried out and histopatholaogy report (BH 1866) was consistent with the arachnoid cyst (Figure 4).

\section{DISCUSSION}

Arachnoid cysts are a congenital disorder and most cases begin during infancy; however, onset may be delayed until adolescence. ${ }^{1}$ Arachnoid cysts can be found on the brain, or on the spine. Intracranial arachnoid cysts usually occur adjacent to the arachnoidal cistern. ${ }^{2,3}$ Spinal arachnoid cysts may be extradural, intradural, or perineural. Arachnoid cysts can be relatively asymptomatic or present with insidious symptoms and for this reason, diagnosis is often delayed.

Symptoms vary by the size and location of the cyst(s), though small cysts usually have no symptoms and are discovered only incidentally. On the other hand,

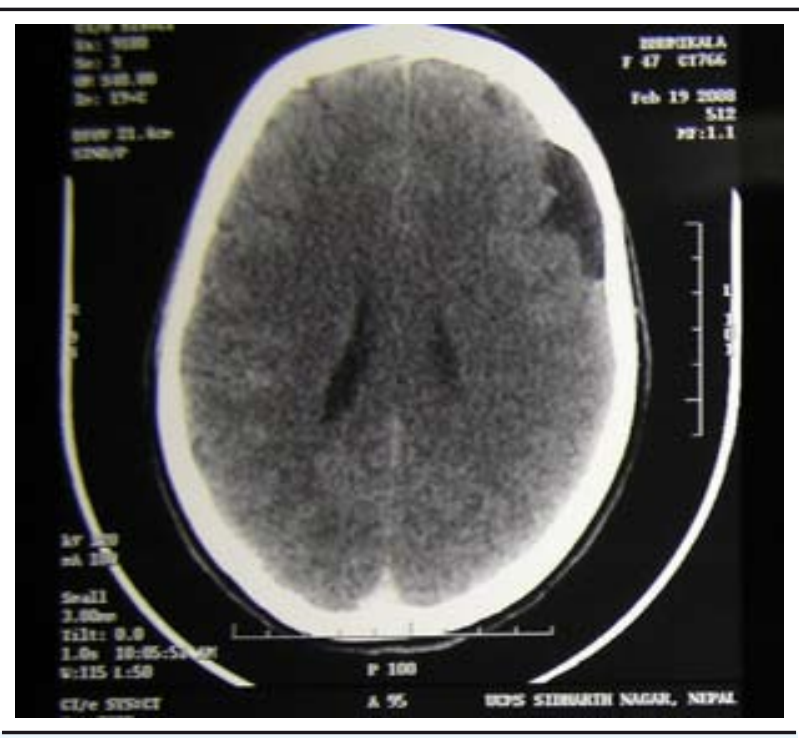

Figure 1. CT scan showing left frontal Arachnoid cyst

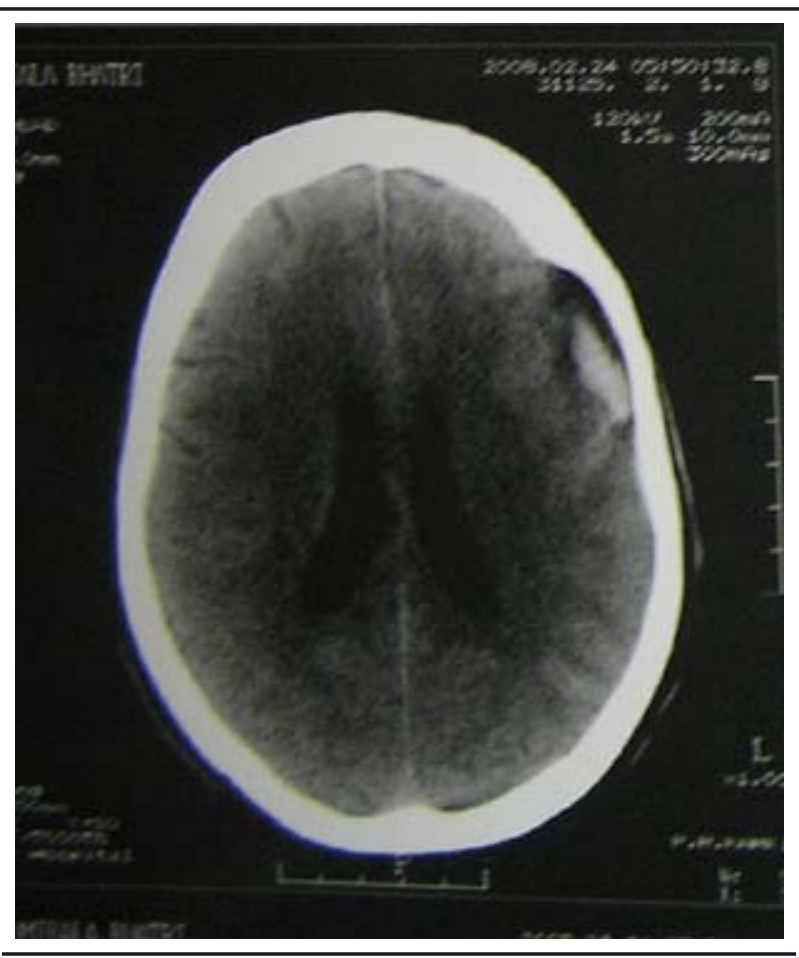

Figure 2. Repeat CT scan showing bleed within the cyst 
Jha et al. Arachnoid Cyst
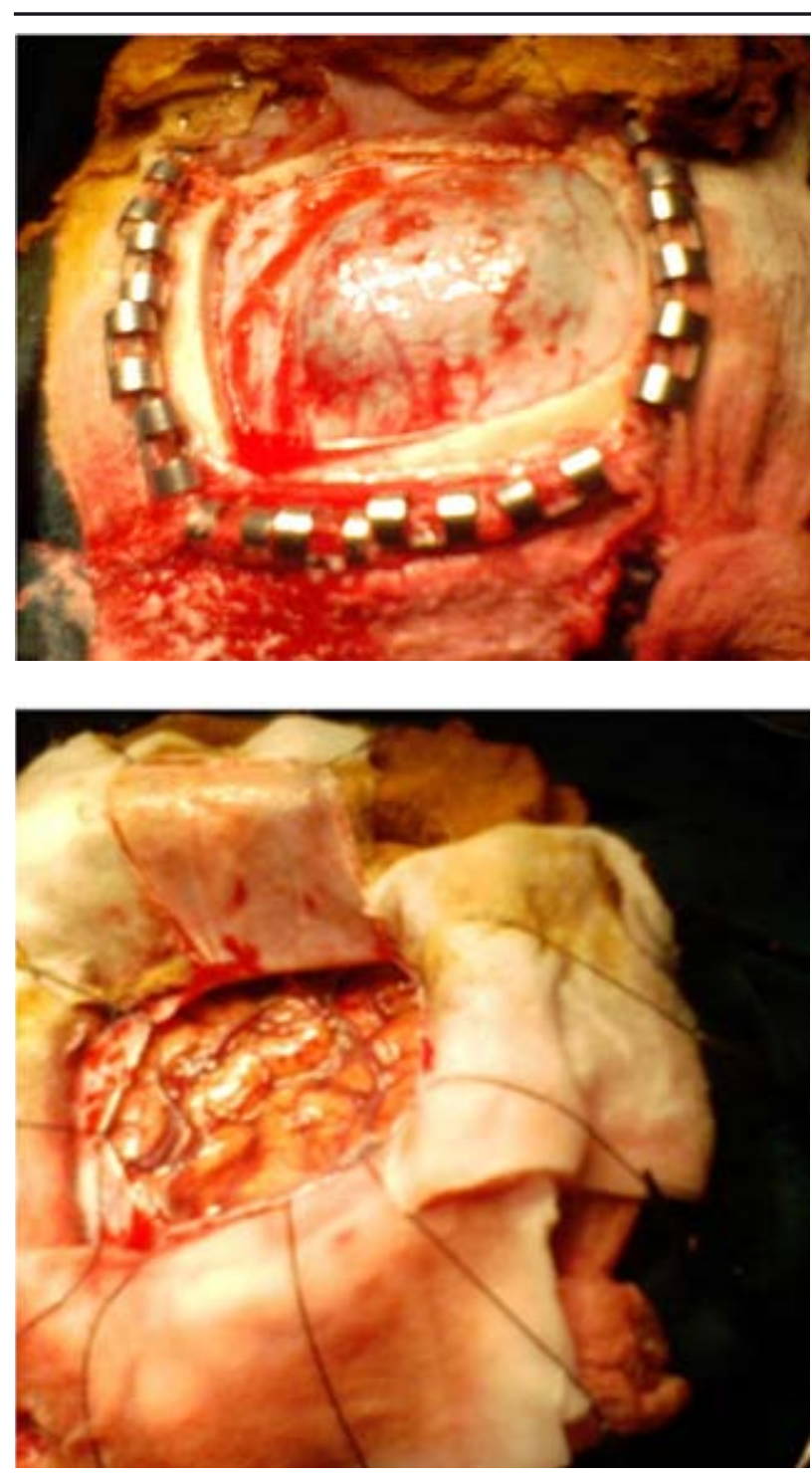

Figure 3. Intraop picture showing the cyst before (3A) and after marsupilisation (3B)

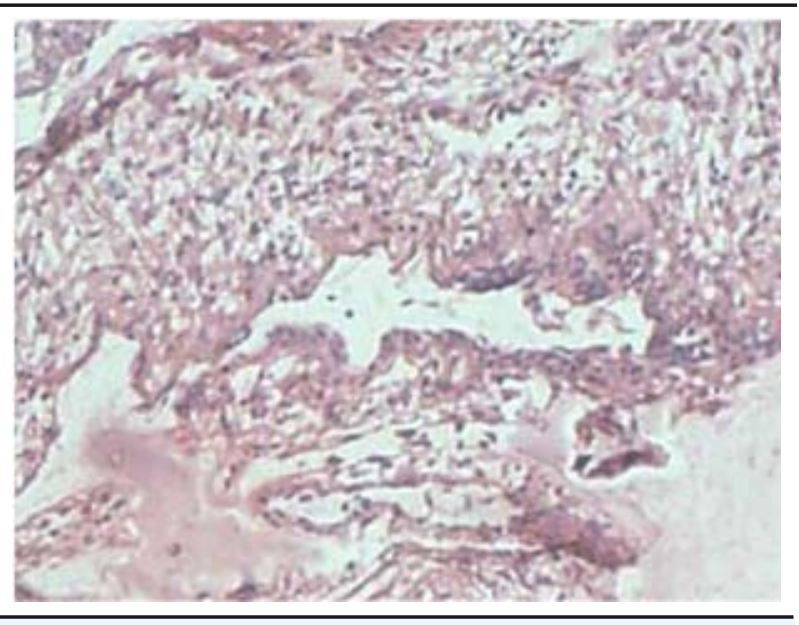

Figure 4. histopathological picture consistent with arachnoid cyst a number of symptoms may result from large cysts: cranial deformation or macrocephaly, bobble-head doll syndrome, headaches, seizures, hydrocephalus, raised intracranial pressure, developmental delay, behavioral changes, hemiparesis, ataxia, pre-senile dementia. In elderly patients (>65 years old) symptoms may be similar to chronic subdural hematoma or normal pressure hydrocephalus.

Symptoms may also differ according to the location. A supratentorial arachnoid cyst can mimic a Ménière's disease attack. ${ }^{4}$ Frontal arachnoid cysts have been associated with depression. ${ }^{5}$ Cysts on the left temporal lobe have been associated with psychosis. ${ }^{6,7}$ A left fronto-temporal cyst more specifically showed symptoms of alexithymia. ${ }^{8}$ Cyst on the right sylvian fissure resulted in new onset of schizophrenia-like symptoms at age $61 .^{9} \mathrm{~A}$ patient with a cyst on the left middle cranial fossa had auditory hallucinations, migraine-like headaches, and periodic paranoia. Patients with left temporal lobe cysts had mood disturbances similar to manic depression (bipolar disorder). ${ }^{10}$

The exact cause of arachnoid cysts is not known. Researchers believe that most cases of arachnoid cysts are developmental malformations that arise from the unexplained splitting or tearing of the arachnoid membrane. According to the medical literature, cases of arachnoid cysts have run in families (familial cases) suggesting that a genetic predisposition may play a role in the development of arachnoid cysts in some individuals. In some cases, arachnoid cysts occurring in the middle fossa are accompanied by underdevelopment (hypoplasia) or compression of the temporal lobe. The exact role that temporal lobe abnormalities play in the development of middle cranial fossa arachnoid cysts is unknown.

In a few rare cases, intracranial arachnoid cysts may be inherited as an autosomal recessive trait. Arachnoid cysts can also occur secondary to other disorders such as Marfan's syndrome, arachnoiditis or agenesis of the corpus callosum.

Diagnosis is principally made by CT or MRI.The differential diagnosis of arachnoid cyst includes porencephalic cyst, hydatid cyst, abscess, gliosis or cystic brain tumours. Treatment for arachnoid cysts is needed when symptoms present. Asymptomatic arachnoid cysts does not need any treatment. A variety of procedures may be used: shunt procedure (internal shunt and cystoperitoneal shunt), craniotomy with excision, marsupilization, endoscopic techniques (fenestration, laser), drainage by needle aspiration or burr hole, reservoir placement and pharmacological treatments. 
Jha et al. Arachnoid Cyst

\section{CONCLUSION}

Overall incidence of Arachnoid cysts are $4 \%$ and intracranial consists of only $1 \% 160 \%$ in middle cranial fossa). Among this $1 \%$ of intracranial arachnoid cyst, incidence of intracranial hemorrhage is $4 \%$ and only less then $0.04 \%$ accounts for intracystic hemorrhage. Hemorrhage into arachnoid cysts has previously been reported following trauma or association with underlying vascular malformations, aneurysm but we have not found any substantial mention in the world literature of the spontaneous intracystic hemorrhage of the arachnoid cyst.

\section{ACKNOWLEDGEMENT}

With thanks to Dr. Karishma Malla Vaidya, senior resident MD Pathology, NAMS for histopathology and Mrs. Lipika Joshi for the computer works.

\section{REFERENCES}

1. Rengachary SS, Kennedy JD. Intracranial arachnoid and ependymal cysts. In: Wilkins RH, Rengachary SS, editors. Neurosurgery. New York: McGraw Hill; 1996. p. 3709-28.

2. Oka Y, Kumon Y, Ohta S, et al. Chronic subdural hematoma associated with middle fossa arachnoid cysts: three case reports, Neurol Med Chir (Tokyo) 1994;34:95-99.

3. Pascual-Castroviejo I, Roche MC, Martínez Bermejo A, Arcas J, García Blázquez M. Primary intracranial arachnoidal cysts. A study of 67 childhood cases. Childs Nerv Syst 1991 Sep;7(5):257-63.

4. Buongiorno G, Ricca G. Supratentorial arachnoid cyst mimicking a Ménière's disease attack. J Laryngol Otol 2003;117(9):728-30.

5. Barker RA, Scolding N, Rowe D, Larner AJ. The A-Z of Neurological Practice: A Guide to Clinical Neurology. Cambridge University Press; 2005. p. 61.
6. Alves da Silva J, Alves A, Talina M, Carreiro S, Guimarães J, Xavier M. Arachnoid cyst in a patient with psychosis: a case report. Annals of General Psychiatry 2007;6:16.

7. Vakis AF, Koutentakis DI, Karabetsos DA, Kalostos GN. Psychosis-like syndrome associated with intermittent intracranial hypertension caused by a large arachnoid cyst of the left temporal lobe. Br J Neurosurg 2006;20(3):156-9.

8. Blackshaw S, Bowen RC. A case of atypical psychosis associated with alexithymia and a left fronto-temporal lesion possible correlations. Can J Psychiatry 1987;32(8):688-92.

9. Cullum CM, Heaton RK, Harris MJ, Jeste DV. Neurobehavioral and neurodiagnostic aspects of late-onset psychosis. Arch Clin Neuropsychol 1994;9(5):371-82.

10. Heinrichs RW. In Search of Madness: Schizophrenia and Neuroscience. Oxford University Press: USA; 2001.p.129. 